\title{
COSMOS Study Microbiological Results: Bacterial Colonization and Infection of Long-Term Peripheral Catheters
}

\section{Juan Luis González López ${ }^{1}$, Paloma Ruiz Hernández ${ }^{1}$ and Kenneth W Strauss ${ }^{2 *}$}

${ }^{1}$ Nursing Department of Universidad Complutense de Madrid (UCM), Instituto de Investigación Sanitaria 'San Carlos' (IdISSC), Madrid, Spain

${ }^{2}$ Global Medical Director, Director of Safety in Medicine, European Medical Association, Brussels, Belgium

\begin{abstract}
Background: Peripheral venous catheters (PVC) have a lower risk of the infection than central venous catheters (CVC), however, their high frequency of use makes PVC a major problem.

Nowadays, there is no consensus regarding the diagnosis of PVC infections and current recommendations are not only utopian but can lead to an underestimation of infection rates.

Objectives: To compare the incidence of bacterial colonization and CRI.

To identify the significant bacterial colonization in $\mathrm{CRI}$, as well as the main pathogens causing bacterial colonization and CRI in long-term PVC.

Material and methods: Nurse-driven, randomized controlled trial to compare closed system (COS) versus open system (MOS), where catheters were removal only by clinical-indication and were inserted and maintained in accordance with CDC guidelines, except those that apply to routine replacement recommendations. The blinded Maki's semiquantitative culture technique was used ClinicalTrials.gov (NCT00665886).

Results: A total of 1183 catheters ( 631 patients) were randomized, 584 in the COS group $(54,173$ catheter-hours recorded), and 599 in the MOS group $(50,296)$. 283 PVC were cultured, i.e. $24 \%$ of the sample.

The mean in-dwell time to onset of event of COS was 239.5 hours compared to 171.9 with MOS.

No significant difference in cumulative incidence or incidence density rates per 1000 catheter-days for bacterial colonization, and no statistical significance were found between rates of CRI (COS, $2.2 \%$; MOS, $2.5 \%$ ). However, we observed a $22 \%$ relative risk reduction (RRR) in CRI with COS.

Of the 283 cultures, $21.9 \%$ were positive, of which the $46.8 \%$ were in COS and $53.2 \%$ in MOS. There were no significant differences between microorganisms isolated, number of colonies or type of germ. Staphylococcus was responsible for $80.3 \%$ of the colonization, and $85.7 \%$ of CRI. S. epidermidis was responsible for $48.8 \%$ of colonization and $52.4 \%$ of CRI. S. aureus was isolated in two cases $(9.5 \%)$, one in each group.

Discussion: As in previous studies, despite a reduction in the incidence of CRI in closed system, the difference did not reach statistical significance.

Nine CRI registered in COS were caused by Gram + (100\%), while in MOS 9 CRI were recorded by Gram + $(75 \%), 2$ by Gram - $(16.7 \%)$ and one by Candida (8.3\%). Our data seems to confirm that bacteria isolated from closed systems are less virulent and/or that these systems may offer protection against CRI.

Conclusion: International guidelines for best clinical practice should differentiate CRI from CRBSI in the management of peripheral lines-related infections.

No statistical differences exist between rates of CRI. However, there is a RRR of CRI with closed systems.

A total of $29 \%$ of the catheter cultured were associated with CRI ( $26.5 \%$ in COS, $31.3 \%$ in MOS), suggesting less virulence of the bacteria isolated in closed systems or greater protection offered by such systems.

In long-term PVC, staphylococci causes $80 \%$ of colonizations, and $100 \%$ of CRI in closed systems and while only $75 \%$ in open

There were no significant differences between isolated bacteria, the number of colonies or the type of pathogen.
\end{abstract}

Keywords: Catheter colonization; Catheter-Related Bloodstream Infection (CRBSI); Catheter-Related Infection (CRI); Clinically indicated; Germs; Safety peripheral venous catheter

\section{Background}

As the use of intravenous devices (IVD) has risen so have the number of serious complications, mainly infectious, associated with its use. In fact, IVD are currently the most important independent cause of nosocomial infection in the health care sector $[1,2]$. Catheter-related infections (CRI) are the leading cause of primary septicemia with a high prevalence leading to increased hospital stays and costs. Furthermore they carry a $3 \%$ mortality [3].

\section{Catheter-related infection in peripheral catheters}

Spanish data from the program of surveillance of infections in patients admitted to critical care units (ICU) shows 6-8 bacteremias/1000 catheter days, of which $10 \%$ of cases were attributable to peripheral venous catheters (PVC).

${ }^{*}$ Corresponding author: Ken Strauss, Global Medical Director, BD, Directo of Safety in Medicine, European Medical Association, Brussels, Belgium, Tel: +32475380454; E-mail: kenneth_strauss@europe.bd.com

Received March 05, 2014; Accepted April 25, 2014; Published April 28, 2014

Citation: López JLG, Hernández PR, Strauss KW (2014) COSMOS Study Microbiological Results: Bacterial Colonization and Infection of Long-Term Peripheral Catheters. Clin Microbial 3: 144. doi:10.4172/2327-5073.1000144

Copyright: (c) 2014 López JLG, et al. This is an open-access article distributed under the terms of the Creative Commons Attribution License, which permits unrestricted use, distribution, and reproduction in any medium, provided the original author and source are credited. 
According to data from the Spanish Society of Infectious Diseases and Clinical Microbiology there were 10,000 bacteremias in spanish patients admitted to ICU. The attributable mortality varies from $14 \%$ to $28 \%$, the average additional hospital stay is 7 days with an additional cost estimated to be $\$ 29,000$ (USA) per episode [4].

While the vast majority of catheter-related bloodstream infection (CRBSI) is associated with central venous catheters (CVC), nosocomial infection has also been linked to many invasive procedures and to the use of devices such as short peripheral catheters, especially in infants $[5,6]$.

However, not all intravenous devices have equal rates of infection. Although the onset of infection and/or phlebitis are maximum-quality indicators of IV therapy with peripheral catheters, in his review of 200 prospective studies, Maki et al. [2] confirmed that only 0.5 cases of CRBSI occurred per 1000 PVC-days (95\% CI: 0.2-0.7). This is similar to data reported for PICC catheters ( 0.8 cases per 1000 catheter-days) and for tunneled central catheters ( 0.9 cases). These figures are far-removed from the 2.9 cases per 1000 catheter days reported with non-tunneled CVC.

Peripheral catheters cause fewer infections, with the risk of CRBSI being less than $0.2 \%$ [7-9]. In prospective studies, the risk of a catheterrelated infection is 2 to 855 times higher with a CVC than with a PVC [10]. However, the sheer number of peripheral catheters used makes them a major health risk and cost.

Recently several authors [11-13] have warned about an increase in the number of infections and bacteremias caused by PVC. These were associated with significant morbidity, mortality and complication rates. What is surprising, but little-known, is that the $87 \%$ primary bacteremias reported were with PVC, according to the National Nosocomial Infection Surveillance System (NNIS) for the 112 medical ICU surveyed in the United States [14].

PVCs have also been recognized as a source of Staphylococcus aureus bacteremia in $12-50 \%$ of all CRBSI $[11,15]$. They are the cause of considerable morbidity and mortality, prolonged hospital stays and an increased cost $[16,17]$ of up to $€ 3,700$ per episode [2].

Despite the central role that PVC has in catheter infections, there is no consensus regarding diagnosis of these infections. The Infectious Diseases Society of America (IDSA) identifies and defines various infectious entities in its current 'Clinical Practice Guidelines for the Diagnosis and Management of Intravascular Catheter-Related Infection' [18]. However, the IDSA gives purely microbiological definitions. There is no mention of infectious entities of primary importance in PVC. These may be diagnosed clinically and microbiologically by a combination of the following manifestations: pain, suppuration, phlebitis, fever of unknown origin, etc.; and colonization of the catheter (significant isolation of $\geq 15$ colony-forming units $\{C F U\}$ of a same microorganism on semiquantitative culture of the tip of the catheter), according to the technique described in 1977 by Maki [19].

These local CRI can become systemic without adequate intervention, but cannot be linked to a CRBSI without a positive blood culture with an identical organism. Nevertheless it is common knowledge that CRI is often a precursor to many CRBSI.

Identifying the bacterial genotype in order to confirm a PVCrelated infection is like killing flies with a cannon: it is a procedure with a high cost and low efficiency and its results are usually irrelevant in practice. In this sense the current IDSA recommendations are not only utopian but can also lead to an underestimation of infection rates and the existing health hazard. In fact, despite the multiplicity of existing alternatives, the Maki technique [19] remains the reference standard in clinical microbiology laboratories for its speed and simplicity [20]. It is considered the 'gold standard' for the diagnosis of CRI in PVC, though not in CVC. In fact, since it is a semiquantitative culture it has poor positive predictive value (PPV) for CRBSI [21-23].

\section{Pathogens causing IRC}

Electron microscopy studies show that the majority of catheters, even those with negative cultures, are colonized by microorganisms. It is estimated that between $30-45 \%$ of catheters have contamination of their tips by a variety of hospital bacteria ( $>75 \%$ Gram-positive cocci such as staphylococci, streptococci and enterococci), without the patient showing any signs of sepsis and with negative blood cultures [24].

The microorganisms that produce catheter infection most frequently are those whose natural habitat is the skin. In fact it has been reported that the Staphylococus epidermidis coagulase-negative group, present ubiquitously on skin, causes more than $50 \%$ of the CRI. Hence handwashing and disinfection insertion sites are critical preventative procedures. The second leading cause of nosocomial infection of PVC ( $44.7 \%$ of cases) is Methicillin-resistant Staphylococcus aureus (MRSA) according to an epidemiological study published in 2000 [25]. Patients infected with a strain of MRSA in the United States were admitted to the hospital for an average of 12 days longer, corresponding to an additional cost of $\$ 27,082$. Anyway, infections caused by all species of S. aureus non-resistant to methicillin extended hospital stay by 4 days on average, and increasing hospital costs by $\$ 9,661$ [26].

Gram-positive skin organisms represent the most commonly reported causative microorganisms of CRBSI [27-30]. Data from SCOPE, a nationwide surveillance study in the United States [24] found that coagulase-negative staphylococci and Staphylococcus aureus account for $31 \%$ and $20 \%$, respectively, of all CRBSI. Enterococcus and Candida species ranked third and fourth, at $9 \%$ each [29]. One quarter of the infections were caused by Gram-negative organisms, with Escherichia coli (6\%) and Klebsiella species being the most common (Table $1[29,31]$ ). Gram-negative organisms, however, have been found to be a more important cause of CRBSI in some areas of the world [32].

Although the risk of bacteremia is lower in peripheral than in central catheters, the sheer number of the former tends to equate the absolute number of episodes. In addition, various authors highlight the greater relative preponderance of episodes due to $S$. aureus in PVC in

\begin{tabular}{|l|c|c|c|}
\hline & \multicolumn{3}{|c|}{ Percentage of BSIs } \\
\hline Pathogen & Total & ICU & Non-ICU \\
\hline Coaqgulase-negative satphylococci & 31.3 & 35.9 & 26.6 \\
\hline Staphylococcus aureus & 20.2 & 16.8 & 23.7 \\
\hline Enterococcus spp. & 9.4 & 9.8 & 9 \\
\hline Candida spp. & 9 & 10.1 & 7.9 \\
\hline Gram-negative rods & & & \\
\hline Escherichia coli & 5.6 & 3.7 & 7.6 \\
\hline Klebsiella spp. & 4.8 & 4 & 5.5 \\
\hline Enterobacter spp. & 4.3 & 4.7 & 3.8 \\
\hline Pseudomonas aeruginosa & 3.9 & 4.7 & 3.1 \\
\hline Acinetobacter baumannii & 1.7 & 2.1 & 1.3 \\
\hline Serratia spp. & 1.3 & 1.6 & 0.9 \\
\hline
\end{tabular}

Table 1: Most common pathogens isolated from nosocomial bloodstream infections, SCOPE $[22,23]$ 
contrast to CVC, with consequent increase in morbidity, mortality and health care costs from S. epidermidis $[8,9,11,15,33,34]$.

Most Fungal-Related Catheter (FRC) infections are due to Candida. In the SCOPE study Candida species ranked fourth among CRBSIcausing microorganisms [9]. A majority of these infections (51\%) were observed in ICUs [29].

\section{Objectives and Definitions}

This secondary analysis of the results of the COSMOS study [35] has as its main objective the presentation of microbiological analyses for:

1. Comparing the incidence in a random sample of catheters of bacterial colonization in both study groups.

Colonization is defined as the presence of $\geq 15 \mathrm{CFU} / \mathrm{ml}$ of a single species of microorganism on semiquantitative culture of the tip of the catheter after it has been removed from the patient and cut using a sterile technique (Figure 1).

2. Comparing the incidence of CRI, defined by the presence of $>15 \mathrm{CFU} / \mathrm{ml}$ of a single species of microorganism in the semiquantitative culture of the catheter withdrawn as a result of phlebitis, pain or fever, or for the disappearance of fever within 24 hours of the withdrawal of the catheter.

Whenever this occurred in the study, the tip of the catheter was cultured.

3. Identify the significant bacterial colonization for CRI in catheters with culture growth.

4. Identifying pathogens that cause bacterial colonization and CRI in PVC that remain in the vein for long periods of time.

\section{Material and Methods}

The COSMOS Study was a nurse-driven, Phase IV, prospective, open label, randomized controlled trial to comparatively evaluation the performance, efficacy, security and costs of safety peripheral integrated closed system BD Nexiva $^{\text {mi }}$ (manufactured by BD, Franklin Lakes, NJ, USA). This interventional group was named COS for 'compact' closed system. It used an all-in-one system consisting of a polyurethane catheter with an integrated $\mathrm{Y}$ extension tubing and a needleless connector split septum named Q-Syte ${ }^{\mathrm{nw}}$. The COS group was compared to an open PVC system using the safety catheter Vasocan ${ }^{\mathrm{Tm}}$ Safety (manufactured by B.

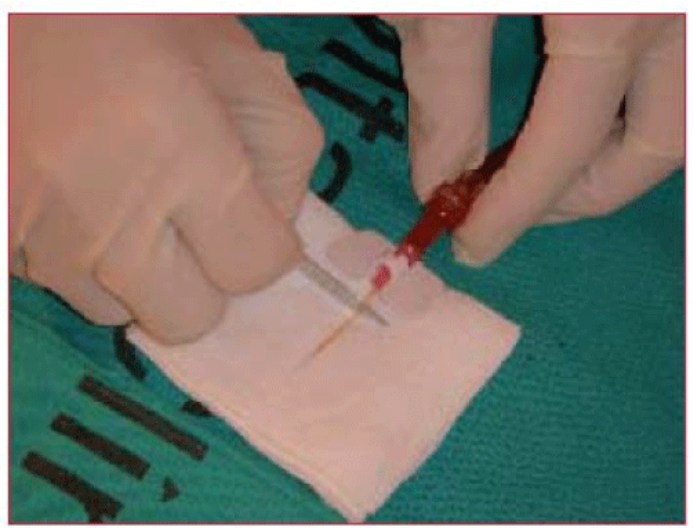

Figure 1: Example of the sterile technique for obtaining catheter tip culture.
Braun, Melsungen, Germany). This group was called MOS for 'mounted' open system. The system consisted of a polytetrafluoroethylene catheter with a three-way tap ('stopcock') and an added $10 \mathrm{~cm}$ extension tubing BD Connecta $\left.{ }^{\text {Tx}}\right)$. In both groups catheters were removal only by clinicalindication in a real world evaluation on 3 hospital wards [36].

This pioneering study was the first to investigate, in a prospective and randomized way, the time that PVC remain in place without complications. The study was performed on three medical (61 beds) and surgical (154 beds) wards at the Hospital Clínico San Carlos (HCSC), a 1000-beds tertiary care university hospital in Madrid, Spain. The trial lasted 108 days and took place between March and July 2008.

The $3 \mathrm{M}$ Tegaderm ${ }^{\mathrm{mw}} 1633$ intravenous dressing (3M Healthcare, St. Paul, MN, USA) was used for both groups. Following manufacturer recommendations, dressings were changed every seven days, or sooner if necessary. Seventy-percent alcohol was used for skin antisepsis and disinfection of access ports. The needleless connector was replaced routinely every eight days (after up to 64 activations), which is less than the 70 activation-limit reported by Adams [37]

PVCs were inserted and maintained in accordance with the guidelines of the US Centers for Disease Control and Prevention (CDC), except that the CDC routine replacement recommendations were not followed. Catheter replacement was performed only if clinically indicated instead of every $72-96$ hours as recommended by the CDC [17].

At least 141 catheters from each group were selected at random and cultured to determine baseline colonization rates. Catheters were evaluated using Maki's semiquantitative culture technique [19]. Laboratory technicians and microbiologists who cultured the catheter tips were blinded as to the study group assignment.

Randomization was computer-generated [38]. The study design, sample size, inclusion and exclusion criteria, and variables with their definitions have been described elsewhere $[35,36]$.

In all analyses, the level of statistical significance was assumed to be $p<0.05$. The post-hoc power of the study was $97 \%$ (Granmo 7.11. Consortion URLEC, Institut Hospital del Mar d'Investigacions Médiques, Barcelona, Spain).

The trial protocol was in accordance with the CONSORT 2010 statement [39], and was registered on the ClinicalTrials.gov, web of the US National Institutes of Health (identifier: NCT00665886). All subjects gave informed consent for the study and it was conducted according to GCP and the guidelines of the Helsinki Protocol.

All statistical analyses were undertaken using Statistical Package for Social Sciences (SPSS for Windows Version 15.0, SPSS Inc., Chicago, IL, USA) and Data Analysis and Statistical Software Version 9.0 (Stata Corp., College Station, TX, USA).

\section{Definition of colonization and infection of peripheral venous catheters in the COSMOS Study}

The COSMOS study, which analyzes the performance of safety PVC, uses the following definitions for colonization and infection:

- Bacterial colonization: growth of $\geq 15 \mathrm{CFU} / \mathrm{ml}$ of the same microorganism on semiquantitative culture of the catheter tip, in the absence of signs of local or systemic infection $[9,19,40,41]$.

- Catheter-Related Infection (CRI): the growth of $\geq 15 \mathrm{CFU} /$ $\mathrm{ml}$ of the same species in semiquantitative culture of catheter tips removed as a result of phlebitis, pain or the suspicion of 
infection due to unexplained fever, or by defervescence within 24 hours of removal catheter $[17,19,42,43]$. A yield of $\geq 15$ CFU/ $\mathrm{ml}$ from a catheter, by means of semiquantitative culture, or a yield of $\geq 10^{3} \mathrm{CFU} / \mathrm{ml}$ from a catheter, by quantitative culture, is considered indicative of catheter-related infection $[19,42]$.

- Catheter-Related Bloodstream Infection (CRBSI) comprises positive semiquantitative culture and blood culture specimens growing the same species without another apparent source for septicemia $[19,40,41,44]$.

- Significant catheter colonization: Growth of $\geq 15 \mathrm{CFU} / \mathrm{ml}$ of the same microorganism on semiquantitative culture of the catheter tip removed as a result of phlebitis, pain or the suspicion of infection due to unexplained fever. Expresses the proportion of culture-positive catheters who presented CRI.

CRI rates were expressed as cases per 1000 PVC days to facilitate the comparison with international data (Category B) $[45,46]$.

\section{Results}

Of 1294 catheters evaluated in 694 patients, 1183 catheters in 631 patients were randomized, 584 in COS group with 54,173 catheterhours recorded, and 599 in MOS group with 50,296 catheter-hours.

Excluding lost catheters, catheter tips were cultured in a randomized fashion. From a total of 364 PVC randomized, 290 were cultured and 283 of these were included in the analysis (128 from MOS and 155 from COS), i.e. $24 \%$ of the total sample.

Demographic data and results of the study variables were recently published [35].

Since catheters were replaced only by clinical indication, many had long indwell times, ranging up to 40.5 days, with a mean of 206,4 hours (95\% CI: 176.1-236.6) and a median of 114.3 hours (95\% CI: $102.6-$ 126.0).

In the population evaluated by Intention to Treat (ITT; $n=1183$ ), mean time till the appearance of a closed systems (COS) event was 239.5 hours (95\% CI: 189.5-289.5), or 10 days, as opposed to 171.9 hours (95\% CI: 149.3-194.5) or 7 days for open systems (MOS). The median time till the appearance of an event was 137 hours (95\% CI: 120.1-154.0) or 6 days for COS and 96 hours (95\% CI: 87.5-104.5) or 4 days for $\operatorname{MOS}(p<0.003)$.

We observed a significant reduction in the rate of phlebitis (36\%), complications $(25 \%)$ and infiltration $(24 \%)$ in the COS group, and this was associated with RRR for painful haematoma (49\%), occlusion (24\%), pain (22\%) and CRI (20\%).

Nevertheless, in ITT population, there was no significant difference in the cumulative incidence (22.6\% COS vs $21.3 \%$ MOS), or in the incidence density rates per 1,000 catheter-days (51.1 COS vs 54.1 MOS) for bacterial colonization, and no statistical significance could be found between the rates of CRI of COS (2.2 per 100 catheters and
5.76 cases/ 1000 catheter-days) and MOS ( 2.5 per 100 catheters and 6.65 cases $/ 1000$ catheter-days). However, observed a $22 \%$ of relative risk reduction (RRR) in CRI with closed system (HR 0.78 CI 95\%: 0.37-1.64; $\mathrm{p}=0.514$ ), as shown in Figure 2.

Although more cases of bacterial colonization were detected in the COS group $(n=37)$ than in the MOS group $(n=33)$, only nine cases of CRI were confirmed in the COS group, compared with 12 cases in the MOS group.

Of the 283 catheters randomized to tip culture and cultivated, $20.5 \%$ (58 catheters) were positive ( $>15$ CFU of the same pathogen), of which $26(44.8 \%)$ were closed systems (COS) and 32 (55.2\%) open systems (MOS). These differences did not reach statistical significance. In catheters randomized to tip culture, there are no significant differences in rates of microbial colonization of closed systems (18.75\%, 42.3 cases per 1000 catheter/days) and open systems (16.12\%, 41.2 cases/1000 catheter/days), $\mathrm{p}=0.923$ (Table 2).

Nor are there statistical difference between rates of CRI of closed systems (1.56\%, 3.5 cases/ 1000 catheter/days) and open systems $(4.51 \%$, 11.5 cases $/ 1000$ catheter/days), $p=0.132$. However, we observed a $69 \%$ RRR in CRI in closed systems randomized to tip culture and cultured (HR 0.31; 95\% CI: 0.03-1.61 (Table 2)).

There were no significant differences between microorganisms isolated, the number of colonies or the type of bacteria between the two groups in terms of catheters randomized to culture. In this study, Staphylococcus was responsible for $80.3 \%$ of catheter colonization, $85.7 \%$ of total CRI, and $100 \%$ of CRI in the COS group. S. epidermidis

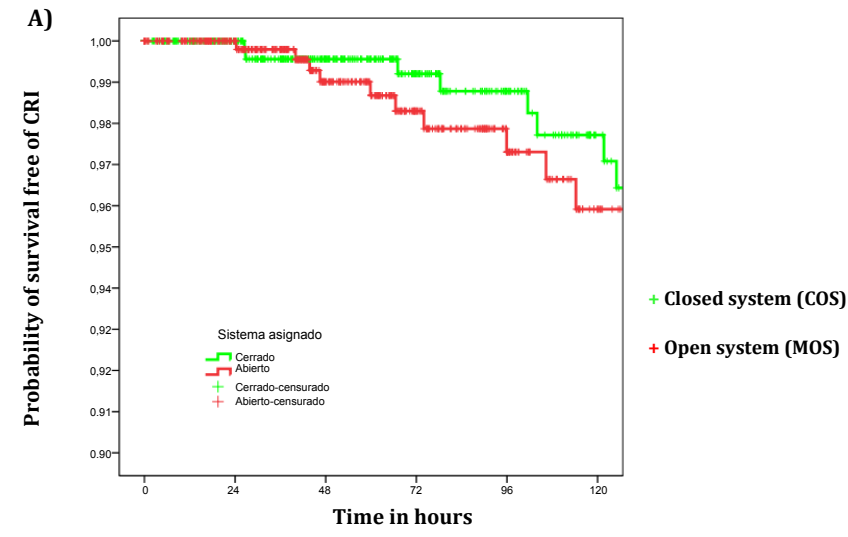

\begin{tabular}{|l|c|c|l|l|}
\hline & $\mathrm{p}$ & HR & \multicolumn{2}{|l|}{$95,0 \%$ CI for HR } \\
\hline & & & Lower & Upper \\
\hline System & 0.514 & 0.781 & 0.371 & 1.643 \\
\hline
\end{tabular}

$\mathrm{CRI}$, catheter-related infection; $\mathrm{p}$, statistical significance; $\mathrm{HR}$, hazard ratio; $\mathrm{Cl}$, confidence interval.

Figure 2: Kaplan-Meier survival curve to the onset of CRI (ITT population).

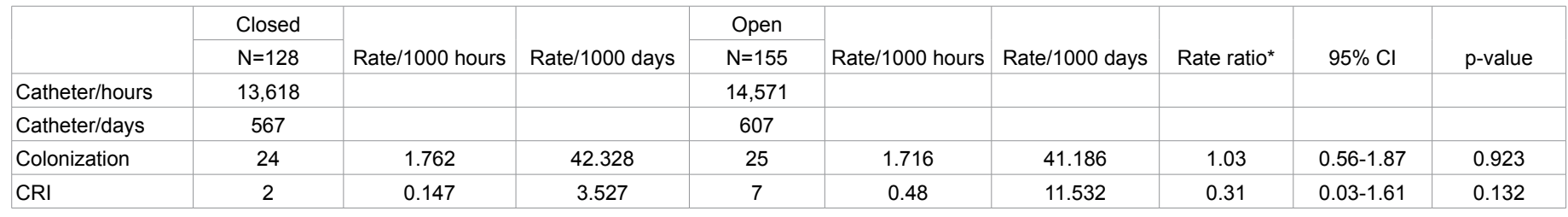

$\mathrm{CRI}$, catheter related ifection; $\mathrm{Cl}$, confidence interval

Table 2: Bacterial colonization and CRI rates in catheters randomized to tip culture and cultivated. 


\begin{tabular}{|c|c|c|c|c|c|}
\hline \multirow{2}{*}{ Germ type } & \multirow{2}{*}{ Germ } & \multicolumn{2}{|c|}{ Colonization } & \multicolumn{2}{|c|}{ CRI } \\
\hline & & $\cos$ & MOS & $\cos$ & MOS \\
\hline \multirow{9}{*}{ Gram + Cocci } & Staphylococcus epidermidis & 17 & 15 & 5 & 6 \\
\hline & Staphylococcus hominis & 8 & 5 & 2 & 2 \\
\hline & Staphylococcus haemolyticus & 0 & 3 & 1 & 0 \\
\hline & Staphylococcus warneri & 1 & 1 & 0 & 0 \\
\hline & S. Coagulasa Negativo & 2 & 0 & 0 & 0 \\
\hline & Subtotal & $28(77.8 \%)$ & $24(80 \%)$ & $8(88.9 \%)$ & $8(66.7 \%)$ \\
\hline & Staphylococcus aureus & 1 & 0 & 1 & 1 \\
\hline & Subtotal & $1(2.8 \%)$ & $0(0 \%)$ & $1(11.1 \%)$ & $1(8.3 \%)$ \\
\hline & Total & $29(80.5 \%)$ & $24(80 \%)$ & $9(100 \%)$ & $9(75 \%)$ \\
\hline \multirow{4}{*}{ Bacilli } & Corynebacterium afermentans & 0 & 0 & 0 & 1 \\
\hline & Eschericha coli & 0 & 0 & 0 & 1 \\
\hline & Otros bacilos & 2 & 1 & 0 & 0 \\
\hline & Total & $2(5.5 \%)$ & $1(3.3 \%)$ & 0 & $2(16.6 \%)$ \\
\hline \multirow{2}{*}{ Fungi } & Candida sp & 0 & 1 & 0 & 1 \\
\hline & Total & $0(0 \%)$ & $1(3.3 \%)$ & $0(0 \%)$ & $1(8.3 \%)$ \\
\hline \multirow{3}{*}{ Mixed } & Various germs & 5 & 4 & 0 & 0 \\
\hline & Total & $5(13.8 \%)$ & $4(13.3 \%)$ & 0 & 0 \\
\hline & TOTAL GROUPS (100\%) & $36(54.5 \%)$ & $30(45.5 \%)$ & $9(43 \%)$ & $12(57 \%)$ \\
\hline
\end{tabular}

${ }^{*}$ Compare rates per 1000 catheter-hours.

Table 3: Colonization and germs causing of $\mathrm{CRI}$ in the COSMOS study.

was responsible for $48.8 \%$ of the PVC colonization and the $52.4 \%$ of cases of CRI. S. aureus was isolated in two of 21 cases $(9.5 \%$ of total $\mathrm{CRI}$ ), one case in each of the study groups (Table 3 ).

\section{Discussion}

\section{Catheter tip colonization}

Maki noted that catheters with less than $15 \mathrm{CFU}$ did not produce bacteremia, unlike those with higher counts. This cutoff had a specificity of $76 \%$ as compared to the gold standard, quantitive culture, and allows us to reduce the number of false positives. However the absolute value of a count of $15 \mathrm{CFU}$ has been questioned [47-50]. Nevertheless we believe that its sensitivity and specificity in catheters removed for suspected infection remain acceptable [47,51]. Given its simplicity it has emerged as the technique of choice in daily clinical practice for the diagnosis of CRI in PVC.

Even with its limitations the Maki technique remains the only viable procedure for the diagnosis and management of infections associated with PVC.

An important limitation of our study was that the protocol required 380 cultures of randomized catheters, as well as cultures of those catheters removed for phlebitis, pain and/or fever of unknown origin (222 cases). However, for various reasons, of the 602 potential cultures only 283 (47\%) were performed.

Nevertheless, with the data obtained, the study micorbiologist conducted a blinded classification of pathogens based on diagnostic costs associated with colonization by certain bacteria, e.g. Staphylococcus aureus. These costs were base don the need for blood analysis, echocardiography, increased stay, etc. Subsequently, the study epidemiologist compared this classification by study groups and found no differences in colonization or microbiological behavior between open and closed systems or between costs attributable to each one.

Our overall findings show a lower rate of colonization of the catheter tip to that reported by Bouza et al. [49] for a closed system with a needleless connector, CLAVE ${ }^{m}$ (52.6/1000 catheters/days in COSMOS study vs 59.2/1000 catheter/days in Bouza study).

The same occurs if we compare colonization rates of closed system in our study (51.1/1.000 catheter/days), representing a reduction of 8 cases per 1000 catheter/days with respect to the results shown by the closed system CLAVE ${ }^{\mathrm{m}}$, despite it was found to be an independent protective against colonization in the Bouza study [49].

This may be due to the fact that catheters were manipulated in COSMOS in a regulated and aseptic fashion and only by nurses. Colonization rates of accesses properly disinfected with $70 \%$ alcohol did not show significant differences in infection rates [50], despite reports in the literature to the contrary [51].

The same occurs if we compare colonization rates of closed system in our study (51.1/1000 catheter/days), representing a reduction of 8 cases per 1000 catheter/days, to results reported with the closed system $\mathrm{CLAVE}^{\mathrm{m}}$, despite it was found to be an independent protective against colonization in the Bouza study [49].

Our rates of bacterial colonization however remain high compared to those reported in 2014 by Mansur et al. [52]. That study put colonization rates in underdeveloped countries at $42.1 \%$. But it must be remembered that the PVC studied in COSMOS had a long indwell time (>206 hours), a duration unmatched in any other published study.

Our data on randomized catheter tip culture and cultivated (Table 2) put the cumulative incidence of colonization at $18.75 \%$ and the rate of incidence density at 42.3/1000 catheter/days. This is in line with data by Mansur et al. [52] and was achieved despite the increased indwell time of the catheters used in COSMOS.

\section{Bacterial colonization and phlebitis}

An association was found between those patients with greater than $15 \mathrm{CFU}$ isolated from catheter tips and with the presence of phlebitis $(p=0,022)$ [53]. Many studies have shown an association between signs of local inflammation and positive catheter culture [19,54-58]. However, COSMOS found a bacterial phlebitis rate of $3.7 \%$ corresponding to 10.1 
cases per 1000 catheter/days for the total sample, significantly lower than that reported in a similar study (9.5\%) [44].

The incidence rate of bacterial phlebitis in our study is $4.3 \%$ and 11.1 cases per 1000 catheter/days with the closed system and $3.2 \%$ and 9.1 cases per 1000 catheter/days in the open system (no statistical difference). This suggests that the higher rates of phlebitis seen in the open systems (101 cases, 17\%, 45 cases/1000 catheter/days, versus 70 cases, $12 \%, 31$ cases/1000 catheter/days in the closed system) are more likely due to mechanical phlebitis than bacterial phlebitis [35].

\section{Catheter-related infection}

In ITT analysis, COSMOS has found a CRI rate of $2.36 \%$, with a median in-dwell time of 114.3 hours and a mean of 206.3 hours. Although this rate is well above the rates of CRBSI in peripheral lines reported by Maki et al. [2], who studied systemic infections in contrast to our study, they are surprisingly and significantly lower than those reported in similar studies (6.9\% [44], 3.4\% [49] and 14\% [52]).

In addition, we found a RRR in CRI of closed systems, with a Vialon $^{\text {Tw }}$ catheter, which goes against the suggestion by Maki and Ringer [9] that higher CRBSI rates are associated with Vialon ${ }^{\text {Tw }}$ than with Teflon. However, as occurred in the study of Bouza et al. [49] and despite a reduction in the incidence of CRBSI in closed system, these differences did not reach statistical significance.

\section{Significant colonization, predictive of CRI}

CRBSI clinically is highly variable and can be confused with other intercurrent processes [58]. It can provoke the removal of catheters on the basis of suspicion. These catheters are culture-negative in up to $80 \%$ of cases [59,60]. In a study of 109 cases of catheters removed for suspected infection, only 40 were confirmed by culture to be infected. There is rarely clinical or laboratory assistance $a$ priori to determine if a catheter is the source of the fever [60].

As in other major issues in IV therapy, there is no agreement on whether bacterial colonization should be considered a recognized forerunner of CRI. Some authors are in favor [61] and some, against [9,44,62]. However, Aygun et al. [41] found that $9.5 \%$ of PVC cultures showed significant growth, and even when significant growth was detected from PVCs, this growth was predictive of a CRBSI in only $43 \%$ of cases.

Significant bacterial colonization among randomized catheters in our study was $17.31 \%$, and was predictive of CRI in $31 \%$ of cases. Only 13 of the 49 culture-positive COS led to CRI as opposed to 15 of the 48 MOS. Our data seems to confirm that bacteria isolated from closed systems are less virulent and that these systems may offer protection against CRI.

\section{Germs causing CRI}

The microbial species most frequently responsible for CVC-related infection are Gram-positive cocci, of which Staphylococci (S. aureus, S. epidermidis) are most frequent. The prevalence of these have remained unchanged over the years (remaining around 75\%). Gram-negative bacteria, especially Enterobacteriaceae and Pseudomonaceae, caused the remaining $25 \%$ of cases [63].

Among Gram-positive bacteria, CNS were the most common isolates. This shows the primary role played by these opportunistic microorganisms in CVC infections [64]. The reason seems to be that for the insertion of the device, an incision must first made for venous access and then the CVC is inserted $[65,66]$. Passage through the skin as well as the manipulation by the medical staff, cause CVC bacterial contamination, and the pathogens are usually normal bacterial flora [63].

In our study, 9 CRI in closed systems were caused by Gram-positives bacteria (100\%), while in open systems 9 CRI were from Gram-positives (75\%), 2 from Gram-negatives (16.7\%) and one from Candida (8.3\%). Thus, there was a greater diversity of CRI-causing pathogens in open systems, and this more closely corresponds to the bacterial distribution reported with CVC [63].

\section{Conclusions}

1. It is necessary that international agencies and their guidelines for best clinical practice differentiate as distinct entities the CRI (which requires the presence of symptoms and positive semiquantitative culture for diagnosis) and the CRBSI (which also requires positive blood cultures for the same species of germ for diagnosis), to facilitate the prevention, diagnosis and control of infections associated with peripheral lines.

2. In catheters cultured there are no significant differences in the rates of microbial colonization between open and closed systems, $\mathrm{p}=0.923$.

3. However, despite their longer in-dwell times, catheters used in COSMOS had lower bacterial colonization rates than those reported by other authors for closed and open systems.

4. Colonization rates of accesses properly disinfected with $70 \%$ alcohol did not show significant differences.

5. The rate of significant bacterial colonization in catheters cultured was $17.31 \%$ and was predictive of CRI in $31 \%$ cases.

6. There are no statistical differences between the rates of CRI between closed and open systems, $\mathrm{p}=0.132$.

7. However, there is a RRR of CRI of $22 \%$ with closed systems. As in the case of Bouza et al. [50] and despite the reduction in the incidence of CRI in closed systems, this difference did not reach statistical significance.

8. Overall $28.9 \%$ of the catheter tips cultured were associated with CRI, $26.5 \%$ in closed systems and $31.3 \%$ in open systems, suggesting a reduced virulence of bacteria isolated in closed systems or greater protection offered by such systems against CRI. This represents a $15.2 \%$ decrease of CRI in closed systems compared with open systems.

9. In long-term peripheral catheters, staphylococci cause $80 \%$ of colonizations for entire sample, and $100 \%$ of CRI in the closed systems and $75 \%$ in open systems.

10. There is no significant difference between the isolated bacteria, the number of colonies or the type of pathogen in both groups.

11. Our data call into question the suggestion of Maki and Ringer [55] that there is more CRBSI associated with Vialon catheters than Teflon ones.

\section{Acknowledgements}

The authors wish to acknowledge their collaboration at research group of the study, composed by J.L. González, E. Fernández, J. Olivares, C. Benedicto, P. Herrera and A. Arribi, as well as Dr. A. Arribi, microbiologist of the study, Dr. J.J. Picazo, Head of Microbiology, and Dr. C. Fernandez, study epidemiologist.

\section{Conflict of Interest Statement}

One of the authors (KWS) is an employee of $\mathrm{BD}$, a manufacturer of severa components used in the COSMOS study. No other conflicts of interest to declare. 
Citation: López JLG, Hernández PR, Strauss KW (2014) COSMOS Study Microbiological Results: Bacterial Colonization and Infection of Long-Term Peripheral Catheters. Clin Microbial 3: 144. doi:10.4172/2327-5073.1000144

\section{Funding sources}

Costs of catheter tip culture and microbiological analyzes were assumed by the Clinical Microbiology Service of the Hospital Clínico San Carlos.

\section{References}

1. Crnich CJ, Maki DG (2005) Infections caused by intravascular devices: epidemiology, pathogenesis, diagnosis, prevention, and treatment. In: APIC Text of Infection Control and Epidemiology. Vol 1. 2nd ed. Association for Professionals in Infection Control and Epidemiology, Inc: Washington DC; p. 24.21-24.26

2. Maki DG, Kluger DM, Crnich CJ (2006) The risk of bloodstream infection in adults with different intravascular devices: a systematic review of 200 published prospective studies. Mayo Clin Proc 81: 1159-1171.

3. Gómez Luque A, Huertas Simonet N, Viciana Ramos MI, Moreno Palacios M, Hernández Pardo PE (2002) [Prophylaxis of infective complications of central venous catheters]. Rev Esp Anestesiol Reanim 49: 17-33.

4. Bouza E, Liñares J, Pascual A (2004) Diagnóstico microbiológico de las infecciones asociadas a catéteres intravasculares. En Cercenado E y Cantón R. Procedimientos en Microbiología Clínica. Recomendaciones de la Sociedad Española de Enfermedades Infecciosas y Microbiología Clínica, Madrid.

5. Stoll BJ, Hansen N, Fanaroff AA, Wright LL, Carlo WA, et al. (2002) Late-onse sepsis in very low birth weight neonates: the experience of the NICHD Neonatal Research Network. Pediatrics 110: 285-291.

6. Urrea M, Iriondo M, Thio M, Krauel X, Serra M, et al. (2003) A prospective incidence study of nosocomial infections in a neonatal care unit. Am J Infect Control 31: 505-507.

7. Centers for Disease Control Working Group (1981) Guidelines for prevention of intravenous therapy-related infections. Infection Control 3: 62-79.

8. Tager IB, Ginsberg MB, Ellis SE, Walsh NE, Dupont I, et al. (1983) An epidemiologic study of the risks associated with peripheral intravenous catheters. Am J Epidemiol 118: 839-851.

9. Maki DG, Ringer M (1991) Risk factors for infusion-related phlebitis with small peripheral venous catheters. A randomized controlled trial. Ann Intern Med 114: 845-854

10. Espina Martínez D, Maldonado Ramírez NE (2008) Mantenimiento de los accesos vasculares en la UCl. Rev Asoc Mex Med Crit y Ter Int 22: 236-240.

11. Pujol M, Hornero A, Saballs M, Argerich MJ, Verdaguer R, et al. (2007) Clinical epidemiology and outcomes of peripheral venous catheter-related bloodstream infections at a university-affiliated hospital. J Hosp Infect 67: 22-29.

12. Estudio de vigilancia de las infecciones nosocomiales en hospitales de Cataluña. VINCAT. Sitio

13. Kallen AJ, Patel PR, O'Grady NP (2010) Preventing catheter-related bloodstream infections outside the intensive care unit: expanding prevention to new settings. Clin Infect Dis 51: 335-341.

14. Richards MJ, Edwards JR, Culver DH, Gaynes, and the National Nosocomial Infections Surveillance System (1999). Nosocomial infections in medical intensive care units in the United States. Crit Care Med 27: 887-892.

15. Trinh TT, Chan PA, Edwards O, Hollenbeck B, Huang B, et al. (2011) Peripheral venous catheter-related Staphylococcus aureus bacteremia. Infect Control Hosp Epidemiol 32: 579-583.

16. Pearson ML (1996) The Hospital Infection Control Practices Advisory Committee. Guideline for prevention of intravascular device- related infections. Am J Infect Control 24: 262-293.

17. O'Grady NP, Alexander M, Dellinger EP, Gerberding JL, Heard SO, et al. (2002) Guidelines for the prevention of intravascular catheter-related infections. Infect Control Hosp Epidemiol 23: 759-769.

18. Mermel LA, Allon M, Bouza E, Craven DE, Flynn P, et al. (2009) Clinical practice guidelines for the diagnosis and management of intravascular catheter-related infection: 2009 Update by the Infectious Diseases Society of America. Clin Infect Dis 49: 1-45.

19. Maki DG, Weise CE, Sarafin HW (1977) A semiquantitative culture method for identifying intravenous-catheter-related infection. N Engl J Med 296: 13051309.

20. Bouza E, Alvarado N, Alcalá L, Sánchez-Conde M, Pérez MJ, et al. (2005) A prospective, randomized, and comparative study of 3 different methods for the diagnosis of intravascular catheter colonization. Clin Infect Dis 40: 1096-1100.

21. Blackett RL, Bakran A, Bradley JA, Halsall A, Hill GL, et al. (1978) A prospective study of subclavian vein catheters used exclusively for the purpose of intravenous feeding. Br J Surg 65: 393-395.

22. Sitges-Serra A, Liñares $J(1988)$ Limitations of semiquantitative method for catheter culture. J Clin Microbiol 26: 1074-1076.

23. Kristinsson KG, Burnett IA, Spencer RC (1989) Evaluation of three methods for culturing long intravascular catheters. J Hosp Infect 14: 183-191.

24. Rugeles S (1991) Manejo de catéteres venosos centrales en nutrición parenteral total. Universitas Medica 32: 135-141.

25. Gil M, Cruz C, Leal N (2000) Características epidemiológicas de la infección por Staphylococcus aureus meticilino resistente en el Hospital Clínico Regional de Valdivia. Cuad cir (Valdivia) 14: 18-22.

26. Gaynes RP (1997) Surveillance of nosocomial infections: a fundamental ingredient for quality. Infect Control Hosp Epidemiol 18: 475-478.

27. Raad I, Hanna H, Maki D (2007) Intravascular catheter-related infections: advances in diagnosis, prevention, and management. Lancet Infect Dis 7: 645657

28. Mermel LA, Maki DG (1994) Infectious complications of Swan-Ganz pulmonary artery catheters. Pathogenesis, epidemiology, prevention, and management. Am J Respir Crit Care Med 149: 1020-1036.

29. Wisplinghoff H, Bischoff T, Tallent SM, Seifert H, Wenzel RP, et al. (2004) Nosocomial bloodstream infections in US hospitals: analysis of 24,179 cases from a prospective nationwide surveillance study. Clin Infect Dis 39: 309-317.

30. Darouiche RO (2003) Nosocomial bloodstream infections and secondgeneration vascular catheters. In Wenzel WP, editor: Prevention and Contro of Nosocomial Infections, 4th ed. Philadelphia: Lippincott Williams \& Wilkins, 281-296.

31. Gaynes R, Edwards JR; National Nosocomial Infections Surveillance System (2005) Overview of nosocomial infections caused by gram-negative bacilli. Clin Infect Dis 41: 848-854.

32. Allegranzi B, Bagheri Nejad S, Combescure C, Graafmans W, Attar H, et al. (2011) Burden of endemic health-care-associated infection in developing countries: systematic review and meta-analysis. Lancet 377: 228-241.

33. Fowler VG Jr, Justice A, Moore C, Benjamin DK Jr, Woods CW, et al. (2005) Risk factors for hematogenous complications of intravascular catheter associated Staphylococcus aureus bacteremia. Clin Infect Dis 40: 695-703.

34. Ekkelenkamp MB, van der Bruggen T, van de Vijver DA, Wolfs TF, Bonten MJ (2008) Bacteremic complications of intravascular catheters colonized with Staphylococcus aureus. Clin Infect Dis 46: 114-118.

35. González López JL, Arribi Vilela A, Fernández del Palacio E, Olivares Corral J, Benedicto Martí C, et al (2014) Indwell times, complications and costs of open vs closed safety peripheral intravenous catheters: a randomized study. J Hosp Infec 86: 117-126.

36. López JL, Del Palacio EF, Marti CB, Corral JO, Portal PH, et al. (2009) COSMOS - a study comparing peripheral intravenous systems. $\mathrm{Br} \mathrm{J}$ Nurs 18 : 844, 846, 848-853.

37. Adams D, Karpanen T, Worthington T, Lambert P, Elliott TS (2006) Infection risk associated with a closed luer access device. J Hosp Infect 62: 353-357.

38. Saghaei M (2004) Random allocation software for parallel group randomized trials. BMC Med Res Methodol 4: 26.

39. Schulz KF, Altman DG, Moher D, for the CONSORT Group (2010) CONSORT 2010 statement: updated guidelines for reporting parallel group randomised trials. BMJ 340: c332.

40. Maki DG, Botticelli JT, LeRoy ML, Thielke TS (1987) Prospective study of replacing administration sets for intravenous therapy at 48- vs. 72-hours intervals. 72 hours is safe and cost-effective. JAMA 258: 1777-1781.

41. Widmer (1997). Prevention and Control of Nosocomial Infections. Baltimore: Williams \& Wilkins.

42. Aygun G, Yasar H, Yilmaz M, Karasahin K, Dikmen Y, et al. (2006) The value of Gram staining of catheter segments for rapid detection of peripheral venous catheter infections. Diagn Microbiol Infect Dis 54: 165-167. 
Citation: López JLG, Hernández PR, Strauss KW (2014) COSMOS Study Microbiological Results: Bacterial Colonization and Infection of Long-Term Peripheral Catheters. Clin Microbial 3: 144. doi:10.4172/2327-5073.1000144

43. Walshe CM, Boner KS, Bourke J, Hone R, Phelan D (2010) Diagnosis of catheter-related bloodstream infection in a total parenteral nutrition population: inclusion of sepsis defervescence after removal of culture-positive central venous catheter. J Hosp Infect 76: 119-123.

44. Bregenzer T, Conen D, Sakmann P, Widmer AF (1998) Is routine replacement of peripheral intravenous catheters necessary? Arch Intern Med 158: 151-156.

45. Joint Commission on the Accreditation of Healthcare Organizations (1994) Accreditation manual for hospitals. In: Joint Commission on the Accreditation of Healthcare Organizations, ed. Chicago, IL: 121-140.

46. National Nosocomial Infections Surveillance System (2004) National Nosocomial Infections Surveillance (NNIS) System Report, data summary from January 1992 through June 2004, issued October 2004. Am J Infect Control 32: $470-485$

47. Rello J, Coll P, Prats G (1991) Laboratory diagnosis of catheter-related bacteremia. Scand J Infect Dis 23: 583-588.

48. Rello J (1992) [Diagnosis of catheter related infection, 15 years later]. Med Clin (Barc) 98: 497-498

49. Bouza E, Muñoz $P$, López-Rodríguez J, Jesús Pérez $M$, Rincón $C$, et al. (2003) A needleless closed system device (CLAVE) protects from intravascular catheter tip and hub colonization: a prospective randomized study. J Hosp Infect 54: 279-287.

50. Arduino MJ, Bland LA, Danzig LE, McAllister SK, Aguero SM (1997) Microbiologic evaluation of needleless and needle-access devices. Am J Infect Control 25: 377-380

51. Casey AL, Burnell S, Whinn $\mathrm{H}$, Worthington $\mathrm{T}$, Faroqui $\mathrm{MH}$, et al. (2007) A prospective clinical trial to evaluate the microbial barrier of a needleless connector. J Hosp Infect 65: 212-218.

52. Mansur FJ, Barai L, Karim MM, Haq JA, Fatema K, et al (2014) Intravascular catheter related infections and antimicrobial susceptibility pattern of isolated bacteria in a tertiary care hospital of Bangladesh. Indian J Med Microbiol 32: 68-71.

53. Hoffmann KK, Western SA, Kaiser DL, Wenzel RP, Groschel DH (1988) Bacteria colonization and phlebitis-associated risk with transparent polyurethane film for peripheral intravenous site dressings. Am J Infect Control 16: 101-106.

54. Ena J, Cercenado E, Martinez D, Bouza E (1992) Cross-sectional epidemiology of phlebitis and catheter-related infections. Infect Control Hosp Epidemiol 13: 15-20.

55. Maki DG, Ringer M (1987) Evaluation of dressing regimens for prevention of infection with peripheral intravenous catheters. Gauze, a transparent polyurethane dressing, and an iodophor-transparent dressing. JAMA 258: 2396-2403.

56. Collin J, Collin C, Constable FL, Johnston ID (1975) Infusion thrombophlebitis and infection with various cannulas. Lancet 2: 150-153.

57. Raad II, Luna M, Khalil SA, Costerton JW, Lam C, et al. (1994) The relationship between the thrombotic and infectious complications of central venous catheters. JAMA 271: 1014-1016.

58. O'Grady NP, Barie PS, Bartlett J, Bleck T, Garvey G, et al. (1998) Practice parameters for evaluating new fever in critically ill adult patients. Task Force of the American College of Critical Care Medicine of the Society of Critical Care Medicine in collaboration with the Infectious Disease Society of America. Crit Care Med 26: 392-408.

59. León MA, León C, Mateu A, Olaechea P, Insausti JM, y el grupo para el estudio de las infecciones relacionadas con catéteres intravasculares en $\mathrm{UCl}$ (1993). Infecciones relacionadas con catéteres intravasculares en el paciente crítico. Estudio Multicéntrico Español. Med Intensiva 17: 531-544.

60. Dobbins BM, Kite P, Wilcox MH (1997) Clinical safety of the endoluminal brush technique for in-situ diagnosis of catheter related sepsis [abstract]. In: Actas 37th Interscience Conference on Antimicrobial Agents and Chemotherapy (Toronto). Washington, DC: American Society for Microbiology.

61. Khare MD, Bukhari SS, Swann A, Spiers P, McLaren I, et al. (2007) Reduction of catheter-related colonisation by the use of a silver zeolite-impregnated central vascular catheter in adult critical care. J Infect 54: 146-150.

62. Rickard CM, Webster J, Wallis MC, et al (2012) Routine versus clinically indicated replacement of peripheral intravenous catheters: a randomised controlled equivalence trial. Lancet 380: 1066-1074.

63. Lombardi S, Scutell M, Felice V, Di Campli E, Di Giulio M, et al. (2014) Centra vascular catheter infections in a Hospital of Central Italy. New Microbiol 37 41-50.

64. Guidet B, Nicola I, Barakett V, Gabillet JM, Snoey E, et al. (1994) Skin versus hub cultures to predict colonization and infection of central venous catheter in intensive care patients. Infection 22: 43-48.

65. Moro ML, Viganò EF, Cozzi Lepri A (1994) Risk factors for central venous catheter-related infections in surgical and intensive care units. The Central Venous Catheter-Related Infections Study Group. Infect Control Hosp Epidemiol 15: 253-264

66. O'grady NP, Alexander M, Dellinger EP, Gerberding JL, Heard SO, et al. (2002) Guidelines for the prevention of intravascular catheter-related infections. Am J Infect Control 30: 476-489. 